\title{
Assessing fire propagation empirical models in shrub fuel complexes using wind tunnel data
}

\author{
E. Marino, M. Guijarro, J. Madrigal, C. Hernando \& C. Diez \\ Centro de Investigación Forestal, INIA, Spain
}

\begin{abstract}
Shrubland are one of the main communities affected by wildland fires, both in forested and unforested areas. However, empirical models predicting fire behaviour in these communities are scarce. One reason explaining the lack of knowledge is the difficulty of obtaining data to develop these kinds of models. Wind tunnel experimental fires have been carried out in different shrubland fuel complexes (Ulex europaeus L. and Pterospartum tridentatum (L.) Willk.) collected in Galicia (NW Spain). Rate of spread data recorded in the laboratory tests have been compared with predictions from existing empirical models. The relationship between the rate of spread values observed in the wind tunnel and the values predicted by different empirical equations obtained in field experimental burns is highly significant, although models overestimate the values observed in the wind tunnel. Nevertheless, the high correlation ( $\mathrm{r}$ between 0.86 and 0.99 ) allows both values to be considered proportional. Even if the laboratory scale is a limiting factor to study fire behaviour, these experiments are simpler, safer and less expensive than the ones carried out in the field. Therefore, laboratory experiments could be an important complementary source of information to field studies in order to further the understanding of fire behaviour in shrubland fuel complexes.
\end{abstract}

Keywords: fire behaviour, rate of spread, shrubland, empirical models, Ulex europaeus L., Pterospartum tridentatum (L.) Willk.

\section{Introduction}

Modelling is progressively more becoming a powerful tool to study fire behaviour. Classically, fire behaviour models are classified as physical, empirical and semi-empirical models. Empirical modelling has resulted in 
significant advances in fire behaviour knowledge, providing simple equations that require readily available fuel and weather data for planning and suppression purposes (Sullivan [1]).

On the other hand, shrubland is one of the main communities affected by wildland fires. However, empirical models predicting fire behaviour in shrubland communities are scarce. One reason explaining the lack of knowledge is the difficulty of obtaining data to develop this kind of models. Some authors have developed empirical models to predict fire rate of spread from field experimental burns performed in different shrubland ecosystems (Van Wilgen et al [2], Marsden-Smedley and Catchpole [3], Vega et al [4-7], Fernandes et al [8, 9], Fernandes [10]). Nevertheless, this type of field experimentation is complex and requires a lot of investment in terms of planning, equipment and human resources. In addition, the unavailability to control most of the variables involved in the process and the uncertainty of weather conditions make this type of experimentation to be a difficult and hard research task.

In contrast, fire laboratory tests are simpler, safer and less expensive than the ones carried out in the field. Moreover, they can provide a certain control on environmental variables, which is required to learn basic mechanisms of fire propagation (Van Wagner [11]). Some authors have performed dimensional analysis to assess the scaling laws in order to define correctly scaled fire laboratory experiments (Byram [12], Lee [13], Emori et al [14], Nelson and Adkins [15], Nelson [16], Pérez et al [17]). Other studies have compared models predictions with observed laboratory data. McAlpine and Xanthopoulos [18] compared observed fire spread rates in wind tunnel fires to predictions from Canadian FBP and American BEHAVE systems. Weise and Biging [19] performed a qualitative comparison of rate of spread prediction for four different models (including physical and empirical models) with observed rate of spread measured in a laboratory experiment in which wind and slope were varied in a tilting wind tunnel. Guijarro et al [20] compared RoS values between wind tunnel data and predictions of three empirical models in shrubland. However, there is little information on the comparison of fire behaviour predicted by empirical models and results observed in laboratory tests.

In the present study, rate of spread data obtained in wind tunnel experimental fires are compared with rate of spread values predicted by several empirical models in order to analyse the existing correlations between both data sets for north-western Iberian Peninsula shrubland fuels.

\section{Material and methods}

\subsection{Laboratory experimental fires}

\subsubsection{Experimental device}

The experimental fires were conducted in an outdoor wind tunnel at INIACIFOR Forest Fires Laboratory in Madrid (Spain), fig. 1. This device consists of a test section and a fan. The test section is $8 \mathrm{~m}$ long with a transversal section of $2 \mathrm{~m}$ wide $\mathrm{x} 3 \mathrm{~m}$ high; on the ground there are eight independent small wagons of 
$1.0 \mathrm{~m}$ long, $0.8 \mathrm{~m}$ wide and $0.25 \mathrm{~m}$ high, filled with sand, where the fuel is arranged. The fan intends to create an air flow, feigning the action of wind within the test section. The fan is controlled by an electronic system which enables to obtain wind speed values between $0 \mathrm{~m} \mathrm{~s}^{-1}$ (when the fan is off) and $7 \mathrm{~m} \mathrm{~s}^{-1}$ in the central part ( 4 central wagons) of the test section. In this case, tests were carried out at wind speeds between $0 \mathrm{~m} \mathrm{~s}^{-1}$ and $3.5 \mathrm{~m} \mathrm{~s}^{-1}$, measured $0.30 \mathrm{~m}$ above the tunnel bare ground, in the central section of the test area.

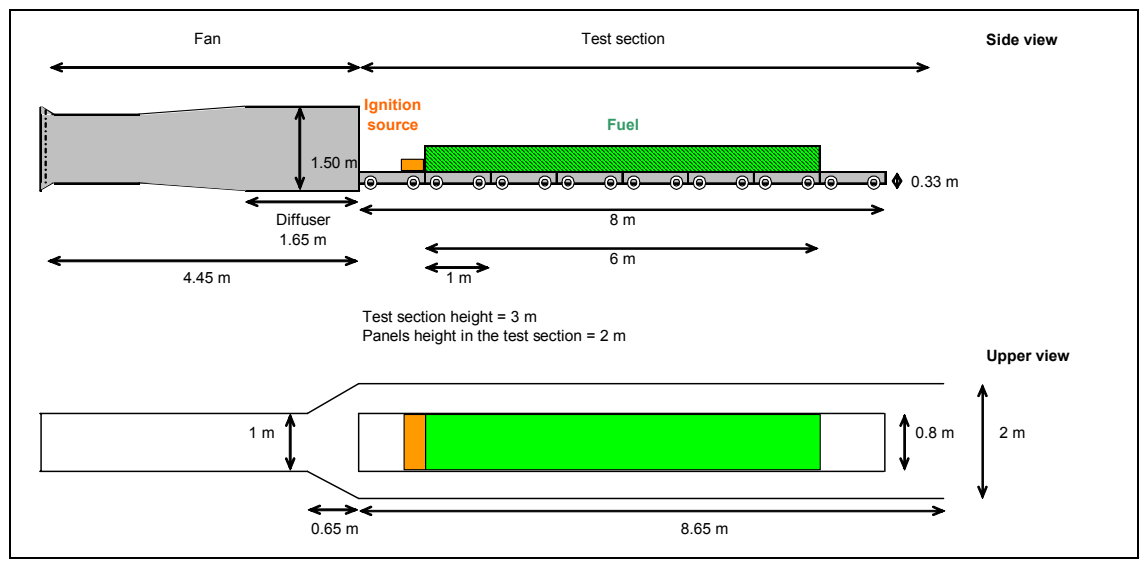

Figure 1: $\quad$ Schematic diagram of the wind tunnel at INIA-CIFOR.

\subsubsection{Shrub fuel complexes}

Two types of shrub fuel complexes were tested:

(a) Pterospartum tridentatum (L.) Willk shrub + Pinus pinaster (Ait) litter.

(b) Ulex europaeus (L.) shrub + litter and herbs present under the shrubs.

These two shrub species were selected because they were dominant in most of the experimental burns carried out in the field to develop the empirical models assessed in this study. Shrub fuels were collected at several representative sites in Galicia (NW Spain). Shrubs were cut at the base of the stems in order to keep the field shrub structure as much as possible, transported in plastic bags to the INIA-CIFOR Laboratory and stored in a cold chamber (at $4^{\circ} \mathrm{C}$ ) to delay water content losses. Pinus pinaster litter of fuel complex (a) was conditioned in the laboratory to a moisture content of $12 \%$.

To construct fuel complex (a), Pinus pinaster needles were uniformly scattered on the six central wagons of the test area. Stems of Pterospartum tridentatum were arranged above the needles in a uniform fashion, with a load of approximately $1.5 \mathrm{~kg} \mathrm{~m}^{-2}$. This fuel arrangement was intended to represent a complex of litter and live understory vegetation. 21 tests were conducted with this fuel complex (a).

In fuel complex (b), fuels were arranged along the six central wagons, preserving field fuel loads of litter+herbs and shrub layers. 3 tests were conducted with this fuel complex (b). 
In both fuel complexes, vegetation cover was $100 \%$. Height of each layer was measured through six measurements points for each layer in each wagon. Moisture content of each layer was obtained through samples collected immediately before conducting each test to determine FMC. The ranges values of environmental and fuels characteristics during the experimental fires are shown in table 1.

A cotton strip impregnated with alcohol was used as ignition source. For each experimental test, fire rate of spread (RoS) was calculated from time took by the fire front (base of the flame) to run along the four central wagons of the test area. Time delays were visually determined and registered with a chronometer.

Table 1: Fuel and environmental characteristics in wind tunnel experimental tests.

\begin{tabular}{|ccccccccc|}
\hline & $\begin{array}{c}\text { Wind } \\
\text { speed } \\
\left(\mathrm{m} \mathrm{s}^{-1}\right)\end{array}$ & $\begin{array}{c}\text { Air } \\
\text { RH } \\
(\%)\end{array}$ & $\begin{array}{c}\text { Litter } \\
\text { FMC } \\
(\%)\end{array}$ & $\begin{array}{c}\text { Litter } \\
\text { Load } \\
\left(\mathrm{kg} \mathrm{m}^{-2}\right)\end{array}$ & $\begin{array}{c}\text { Shrub } \\
\text { live } \\
\text { FMC } \\
(\%)\end{array}$ & $\begin{array}{c}\text { Shrub } \\
\text { dead } \\
\text { FMC }^{*} \\
(\%)\end{array}$ & $\begin{array}{c}\text { Shrub } \\
\text { Load } \\
\left(\mathrm{kg} \mathrm{m}^{-2}\right)\end{array}$ & $\begin{array}{c}\text { Shrub } \\
\text { Height } \\
(\mathrm{m})\end{array}$ \\
\hline Min & 0 & 27.0 & 10.0 & 0.5 & 26.5 & 22.4 & 0.5 & 0.36 \\
Max & 3.5 & 78.0 & 36.6 & 1.5 & 105.8 & 33.5 & 3.6 & 0.71 \\
\hline
\end{tabular}

*Only in fuel complex (b).

\subsection{Empirical models for shrubland fuels}

Several empirical models by Vega et al [4-7] and Fernandes et al [8,9] predicting fire rate of spread (RoS) for different shrubland ecosystems in Galicia (NW Spain) and Portugal were selected, table 2.

In Galicia, the model in Vega et al [4] was developed from experimental burns conducted in three types of shrubland communities: low mixed-heather shrub, shrub complex dominated by Pterospartum tridentatum, and gorse (Ulex sp.) shrubland, where wind speed (U), slope (S) and fuel height (H) are the independent variables, eqn. (1). A very similar model was later developed by Vega et al [5] for the same type of shrubland fuels and with the same independent variables, eqn. (2). Another model including not only wind, slope and fuel height as independent variables but also shrub cover (Pcob) was published in Vega et al [6], eqn. (3). More recently, Vega et al [7] developed an empirical model with experiments conducted in north-western Iberian shrubland ecosystems (gorse shrubland, mixed heathland of Erica umbellata, Ulex minor and Pterospartum tridentatum, and Erica australis-Pterospartum tridentatum heathland. This model included only wind speed and slope as independent variables, i.e. the model was not dependent from fuel characteristics, eqn. (4).

In Portugal, Fernandes et al [8] developed an empirical model for RoS prediction using microplot data in Erica umbellata Loefl. and Pterospartum tridentatum shrubland, with wind speed and shrub height as independent variables, eqn. (5). Another model by Fernandes et al [10] was developed for litter + shrubs fuel complex typically found under Pinus pinaster Ait. stands in Portugal, adding litter moisture content (Msd) to the model, eqn. (6). Other 
models by Fernandes [10] were not tested due to the lack of required input data set from the laboratory tests.

Table 2: $\quad$ Empirical models assessed.

\begin{tabular}{|lll|}
\hline \multicolumn{1}{|c|}{ Model } & \multicolumn{1}{c|}{ Equation } \\
\hline Vega_1998 & $\operatorname{RoS}=0.249 \mathrm{U}^{1.193} \mathrm{H}^{0.658} \exp ^{1.088 \mathrm{~S}}$ \\
Vega_2000 & $\operatorname{RoS}=4.84 \mathrm{U}^{1.13} \mathrm{H}^{0.49} \exp ^{0.77 \mathrm{~S}}$ & (1) \\
Vega_2001 & $\mathrm{RoS}=1.94\left(\mathrm{U}+\exp ^{\mathrm{S}}\right)^{1.12} \operatorname{Pcob}^{-0.83} \mathrm{H}^{0.19}$ & (3) \\
Vega_2006 & $\mathrm{RoS}=1.43 \mathrm{U}^{1.152} \exp ^{0.039 \mathrm{~S}}$ \\
Fernandes_2000 & $\mathrm{RoS}=0.0869 \mathrm{U}^{1.83} \mathrm{H}^{1.47}$ & (4) \\
Fernandes_2002 & $\mathrm{RoS}=1.906 \mathrm{U}^{0.868} \exp ^{(-0.035 \mathrm{Msd}+0.058 \mathrm{~S})} \mathrm{H}^{0.635}$
\end{tabular}

\subsection{Statistical analysis}

Linear regression analyses were performed to assess the relationships between laboratory data and the predicted values calculated by empirical models. For each model, predicted rate of spread values were fitted to eqn. (7):

Predicted $\operatorname{RoS}=\mathrm{a}+\mathrm{b}$ [observed RoS]

where [observed RoS] is the fire rate of spread obtained in the wind tunnel experiments. Regression coefficients $(\mathrm{a}, \mathrm{b})$ and Pearson correlation coefficient $(\mathrm{r})$ were calculated for each model, and the corresponding statistical significance level was assessed. A minimum coefficient of determination $\left(\mathrm{R}^{2}\right)$ value of $75 \%$ was chosen as a threshold for predicted and observed RoS to be considered proportional values. In order to assess proportionality scale, a proportionality factor $(k)$ was calculated for laboratory data as the mean value of the coefficient predicted/observed for each model. Observed RoS data from the wind tunnel burns were assessed both together and separated in two data sets according to the shrub moisture contents tested: low live moisture level (shrub FMC $<60 \%$ ) and high live moisture level (shrub FMC $>60 \%$ ).

\section{Results}

All linear correlations between empirical models and laboratory data were highly significant $(\mathrm{p}<0.000)$, table 3 . Stronger correlations $(\mathrm{r}>0.98)$ were obtained for lower fuel moisture levels (shrub FMC $<60 \%$ ) in all the models tested, table 3-a. Nevertheless, higher fuel moisture levels (shrub FMC $>60 \%$ ) also showed a quite strong relationship between observed and predicted $\operatorname{RoS}(0.86<\mathrm{r}<0.94)$, table 3-b. Attempting to fit all data (i.e. independently of shrub FMC) resulted in similar values than the ones obtained when fitting only the high FMC level data set, showing a slight correlation decrease $(0.85<\mathrm{r}<0.92)$, table 3-c.

As regards proportionality, the models overpredicted observed laboratory $\mathrm{RoS}$ at different scales. The proportionality factor $(\mathrm{k})$ was lower at lower fuel moisture levels for all models, ranging from 1.13 to 6.14 , table 3 -a, whereas at higher fuel moisture levels the $\mathrm{k}$ factor was increased in all cases, ranging from 2.83 to 13.24 , table $3-b$. Finally, considering the whole data set, the $\mathrm{k}$ factor 
showed intermediate values between the ones obtained for low and high FMC data sets separately, table 3-c (from 2.05 to 9.84).

Table 3: $\quad$ Summary of resulting regression coefficients $(\mathrm{a}, \mathrm{b})$, determination coefficient $\left(\mathrm{R}^{2}\right)$, correlation coefficient $(\mathrm{r})$, significance level of the fit (p) and proportionality factor $(\mathrm{k})$ obtained for each model and data set: a) low moisture content, b) high moisture content, and c) all data.

\begin{tabular}{|c|c|c|c|c|c|c|}
\hline \multicolumn{7}{|c|}{ a) Low moisture content (shrub FMC $<60 \%$ ) } \\
\hline Model & $\mathrm{a}$ & $\mathrm{b}$ & $\mathrm{R}^{2}$ & $\mathrm{R}$ & $\mathrm{p}$ & $\bar{K}$ \\
\hline Vega_1998 & -3.946 & 12.349 & 0.986 & 0.993 & 0.000 & 5.82 \\
\hline Vega_2000 & -3.511 & 11.745 & 0.987 & 0.993 & 0.000 & 5.87 \\
\hline Vega_2001 & 0.018 & 6.079 & 0.986 & 0.993 & 0.000 & 6.14 \\
\hline Vega 2006 & -1.843 & 6.025 & 0.989 & 0.994 & 0.000 & 2.95 \\
\hline Fernandes_2000 & -1.564 & 3.573 & 0.963 & 0.981 & 0.000 & 1.13 \\
\hline Fernandes_2002 & -0.900 & 5.156 & 0.969 & 0.984 & 0.000 & 3.51 \\
\hline \multicolumn{7}{|c|}{ b) High moisture content (shrub FMC $>60 \%$ ) } \\
\hline Model & $\mathrm{a}$ & $\mathrm{b}$ & $\mathrm{R}^{2}$ & $\mathrm{R}$ & $\mathrm{p}$ & K \\
\hline Vega_1998 & -1.460 & 18.000 & 0.834 & 0.913 & 0.000 & 13.24 \\
\hline Vega_2000 & -1.311 & 17.378 & 0.854 & 0.924 & 0.000 & 13.08 \\
\hline Vega_2001 & 1.001 & 9.221 & 0.879 & 0.938 & 0.000 & 11.19 \\
\hline Vega_2006 & -1.070 & 9.330 & 0.891 & 0.944 & 0.000 & 6.43 \\
\hline Fernandes_2000 & -0.686 & 4.764 & 0.751 & 0.867 & 0.000 & 2.83 \\
\hline Fernandes_2002 & -0.015 & 6.398 & 0.828 & 0.910 & 0.000 & 5.78 \\
\hline \multicolumn{7}{|c|}{ c) All data } \\
\hline Model & $\mathrm{a}$ & $\mathrm{b}$ & $\mathrm{R}^{2}$ & $\mathrm{R}$ & $\mathrm{p}$ & $\mathrm{K}$ \\
\hline Vega_1998 & -0.641 & 12.397 & 0.750 & 0.866 & 0.000 & 9.84 \\
\hline Vega_2000 & -0.416 & 11.854 & 0.756 & 0.869 & 0.000 & 9.78 \\
\hline Vega_2001 & 1.568 & 6.194 & 0.763 & 0.873 & 0.000 & 8.88 \\
\hline Vega_2006 & -0.400 & 6.204 & 0.771 & 0.878 & 0.000 & 4.84 \\
\hline Fernāndes_2000 & -0.612 & 3.504 & 0.735 & 0.857 & 0.000 & 2.05 \\
\hline Fernandes_2002 & -0.024 & 5.121 & 0.847 & 0.920 & 0.000 & 4.74 \\
\hline
\end{tabular}

Concerning Vega et al models, Vega_2006 was the model showing a lower $\mathrm{k}$ factor $(\mathrm{k}=2.95$ for low shrub moisture, $\mathrm{k}=6.43$ for high shrub moisture) as well as a better fit $\left(\mathrm{R}^{2}=99 \%\right.$ for low shrub moisture, $\mathrm{R}^{2}=89 \%$ for high shrub moisture), table 3 .

Comparing results among the models by Fernandes et al, Fernandes_2000 was the model that showed the most similar values between observed and predicted RoS, with $\mathrm{k}=1.13$ for low shrub moisture, and $\mathrm{k}=2.83$ for high shrub moisture. However, the model Fernandes_2002 showed a better fit with observed RoS, especially for high shrub moisture level $\left(\mathrm{R}^{2}=97 \%\right.$ for low moisture, $\mathrm{R}^{2}=83 \%$ for high moisture), table 3 .

\section{Discussion}

The results, table 3, showed that observed RoS in laboratory fires is always overpredicted by the assessed empirical models. Similar trend was obtained by 
McAlpine and Xanthopoulos [18] when comparing observed fire spread rates in ponderosa pine fuel beds to estimates computed by the empirical Canadian Forest Fire Behaviour Prediction System. According to these authors, two primary reasons could explain the prediction errors: the experimental design and the wind speed estimation. In the present study, two types of possible causes have been considered: causes linked to the experimental device and causes related to fuel characteristics.

Concerning the experimental device, one problem could be the wind profile simulated in the wind tunnel, which may not be the same as the one in the field. Besides, conversion of the wind tunnel wind velocity, measured at $0.30 \mathrm{~m}$ before the fuel bed were arranged, to an equivalent 2-m or 6-m (depending on the assessed model) open wind speed depends on the chosen conversion factors, that are extremely variable in the available literature. Since the assessed fire behaviour prediction models are highly sensitive to changes in wind speed, small errors choosing the conversion factors can induce important prediction errors, as McAlpine and Xanthopoulos [18] also pointed out. Dimensions of the wind tunnel may also influence the fire behaviour, being no long enough to reach the equilibrium head RoS.

With regard to fuel characteristics, they could be, in some cases, not exactly the same as the ones in the field. For example, one of the differences between field and laboratory fires is that fuels tested in the wind tunnel were conditioned in a chamber inside the laboratory, and were only arranged in the outdoor experimental device immediately before conducting the tests. Therefore, the presumed equilibrium between FMC levels and environmental conditions may not be achieved. Nevertheless, air temperature and relative humidity, as surrogates of dead fuel moisture, are in general found to be variables of minor importance to explain RoS variation in these fuel complexes (Vega et al [7]).

Despite the above discussed overprediction, results of the present study showed a highly significant linear relationship between observed and predicted RoS. Moreover, the high correlation coefficients obtained indicate that laboratory experiments can provide proportional RoS values compared to the ones predicted with field experimental fires. As regards the comparison between the empirical models tested, the best correlations with wind tunnel data were obtained for the model by Vega et al [7], which is the only model developed with the integration of data from northern Spanish and Portuguese shrubland field burns. Nevertheless, very strong correlations were also obtained for the rest of the models, especially for Vega et al [4-6] models at low levels of FMC. In contrast, the models by Fernandes et al $[8,9]$ predicted more similar RoS values.

In the case of the model showing the best fit, eqn. (4), RoS is independent from fuel characteristics. Moreover, the only factor assessed in the present study affecting predicted RoS variation was the wind speed because, in our case, the term including the slope is eliminated ( $\mathrm{S}$ was equal to zero in all laboratory fires). In the rest of the assessed models, wind is also the main variable explaining the most part of RoS variation. Therefore, the results indicate that, in the range of conditions tested and in spite of the problems concerning wind characteristics in the wind tunnel, RoS variations due to differences in wind 
speed are very similar between laboratory and field experimental burns. These findings suggest that, in certain cases, wind effects on fire propagation can be accurately assessed in the wind tunnel despite the scale differences, which could be easily corrected, at least in the type of fuel complexes and range of conditions tested, by means of the corresponding proportionality factor $(\mathrm{k})$.

In all models, better correlations were obtained when fitting low and high shrub moisture content data sets separately, and higher $\mathrm{R}^{2}$ were observed for lower fuel moisture content levels. Different proportionality scale was also observed between both levels of FMC. The results indicate a different effect of FMC on fire propagation at laboratory scale, showing more accurate predictions and more similar values of RoS for lower fuel moisture content levels. Vega et al [6] suggested that fuel moisture may be a key variable determining fire propagation success in a way that above a certain threshold fire would not be sustained, and below that threshold propagation may be independent of fuel moisture level. This argument may explain the different results observed in the wind tunnel between the two fuel moisture data sets. Nevertheless, the effect of fuel moisture content on fire behaviour should be further study in laboratory.

\section{Conclusions}

In spite of the rate of spread overestimation by the empirical models tested, the relationships found between the observed values in the wind tunnel and the models predictions was highly significant. Moreover, the high correlation coefficients obtained allows both values to be considered proportional. Even if the laboratory scale is a limiting factor to study fire behaviour, these experiments are a relatively safe and inexpensive method to assess the existing relationships between the different variables involved in shrubland fires (Burrows [21]), because laboratory tests provide the advantage to yield relationships between fire propagation and independent variables under certain control and, therefore, repeatable conditions (Van Wagner [22]).

A single approach to predict wildland fire behaviour is not suitable for all purposes (Morvan et al [23]), and thus it is important to assess and integrate complementarities between the different methodologies to model forest fires (Van Wagner [22]). The results of this study confirm the wind tunnel data as a useful complementary source of information to field studies in order to further the understanding of fire behaviour in shrubland fuel complexes. Nevertheless, further research is needed to assess new models and other fuel types. Future work is also needed to study if this kind of correlation would continue to be present after fuel reduction treatments, which could give the opportunity to easily test different fuel treatments under a wider range of conditions.

\section{Acknowledgements}

This study was supported by the Spanish Ministry of Education and Science and FEDER Funds through Project RTA05-00244-C02-02, and by the European Commision, through the Project FIRE STAR (EVG1-CT-2001-00041). We 
thank the staff of the Departamento de Protección Ambiental, CINAM-Lourizán, partner in both Projects, for field assistance.

\section{References}

[1] Sullivan, A., A review of wildland fire spread modelling, 1990-present, 2: Empirical and quasi-empirical models, arXiv:0706.4128v1[physics.geoph], 32 pp, 2008.

[2] Van Wilgen, B.W., Le Maitre, D.C. \& Kruger, F.J., Fire behaviour in South African fynbos (macchia) vegetation and predictions from Rothermel's fire model. J. Appl. Ecol., 22, pp. 207-216, 1985.

[3] Marsden-Smedley, J.B. \& Catchpole, W.R., Fire behaviour modelling in Tasmanian buttongrass moorlands. II. Fire behaviour. Int. J. Wildland Fire, 5, pp. 215-228, 1995.

[4] Vega, J.A., Cuiñas, P., Fonturbel, T., Pérez-Gorostiaga, P. \& Fernandez, C., Predicting fire behaviour in Galician (NW Spain) shrubland fuel complexes. Proc. of the $3^{\text {rd }}$ Int. Conf. Forest Fire Research \& $14^{\text {th }}$ Fire and Forest Meteorology, ed. Viegas, D.X., Coimbra, pp. 713-728, 1998.

[5] Vega, J.A., Cuiñas, P., Fonturbel, T., Pérez-Gorostiaga, P. \& Fernandez, C., Desarrollo de nuevos modelos de predicción del comportamiento del fuego (Chapter 9.3). La defensa contra incendios forestales. Fundamentos y experiencias, ed. Vélez, R., McGraw-Hill, Madrid, pp. 9.11- 9.20, 2000.

[6] Vega, J.A., Pérez-Gorostiaga P., Cuiñas, P., Fonturbel, T., \& Fernández, C. Manual de queimas prescritas para matogueiras de Galicia, Xunta de Galicia, Consellería de Medio Ambiente, 2001.

[7] Vega, J.A., Fernandes, P., Cuiñas, P., Fonturbel, T., Pérez, J.R. \& Loureiro, C., Fire spreads analysis of early summer field experiments in shrubland fuel types of Northwestern Iberia. Proc: of the $5^{\text {th }}$ Int. Conf. on Forest Fire Research, ed. Viegas, D.X., Coimbra, 2006.

[8] Fernandes, P., Catchpole, W.R. \& Rego, F., Shrubland fire behaviour modelling with microplot data. Can. J. For. Res., 30, 889-899, 2000.

[9] Fernandes, P., Botelho, H.S. \& Loureiro, C., Models for the sustained ignition and behaviour of low-to-moderately intense fires in maritime pine stands. Proc. of the $4^{\text {th }}$ Int. Conf. on Forest Fire Research, ed. Viegas, D.X., Coimbra, 2002.

[10] Fernandes, P., Fire spread prediction in shrub fuels in Portugal. Forest Ecology and Management, 144, pp.67-74, 2001.

[11] Van Wagner, C.E., Two solitudes in forest fire research, Information Report PS-X-29, Canadian Forestry Service, Petawawa Forest Experiment Station, Chack River, Ontario, Canada, 1971.

[12] Byram, G.M., Scaling laws for modeling mass fires. Pyrodynamics, 4, pp. 271-284, 1966.

[13] Lee, B.T., Laboratory scaling of the fluid mechanical aspects of large fires. Combust. Sci. Technol., 4, pp. 233-239, 1972.

[14] Emori, R.I., Iguchi, Y., Saito, K. \& Wichman, I.S., Simplified scale modeling of turbulent flame spread with implication to wildland fires. 
Proc. of the $2^{\text {nd }}$ International Symposium on Fire Safety Science, ed. Wakamatsu, T. et al., New York, pp. 263-273, 1988.

[15] Nelson, R.M., \& Adkins, C.W., A dimensionless correlation for the spread of wind-driven fires. Can. J. Forest Res., 18, pp. 391-397, 1988.

[16] Nelson, R.M. Jr., An effective wind speed for models of fire spread. Int. J. Wildland Fire., 11, pp. 153-161, 2002.

[17] Pérez, Y., Àgueda, A., Pastor, E. \& Planas, E., Study of the effect of changing scale in forest fires experimentation by means of dimensional analysis. Proc. of the $5^{\text {th }}$ Int. Conf. on Forest Fire Research, ed. Viegas, D.X., Coimbra, 2006.

[18] McAlpine, R.S. \& Xanthopoulos, G., Predicted vs observed fire spread rates in ponderosa pine fuel beds: a test of American and Canadian systems. Proc. of the $10^{\text {th }}$ Conference on Fire and Forest Meteorology, Ottawa, Canada, 1989.

[19] Weise, D.R. \& Biging, G.S., A qualitative comparison of fire spread models incorporating wind and slope effects. Forest Science, 43 (2), pp. 170-180, 1997.

[20] Guijarro, M., Madrigal, J., Díez C. \& San Martín, J. Caracterización de la propagación del fuego en matorral de carqueixa mediante quemas en túnel de viento. Actas del $4^{\circ}$ Congreso Forestal Español, ed. Sociedad Española de Ciencias Forestales, 2005.

[21] Burrows, N.D., Fire behaviour in jarrah forest fuels. 1. Laboratory experiments. CALMScience, 3(1), pp. 31-56, 1999.

[22] Van Wagner, C.E., Fire behaviour modelling - how to blend art and science. Proc. of the $8^{\text {th }}$ Conference on Fire and Forest Meteorology, ed. Society of American Foresters, USA, 1985.

[23] Morvan, D., Larini, M., Dupuy, J.L., Fernandes, P., Miranda, A., Andre, J., Sero-Guillaume, O., Calogine, D. \& Cuiñas, P., Behaviour modelling of wildland fires: a state of the art. Deliverable D-03-01, EUFIRELAB, 2004. 